\title{
Tourism as a tool of development: the case study of Siwa oasis - Egypt western desert
}

\author{
D. F. Amara \\ Arab Academy for Science and Technology and Maritime Transport, \\ College of Management and Technology, \\ Hotels and Tourism Department, Alexandria, Egypt
}

\begin{abstract}
Challenges confronting the world's visitor attractions vary both in scale and nature according to their location and ecosystem. Tourism is generally regarded as less destructive to the environment than most other industries; nevertheless, its sheer size and widespread presence create negative physical and social environmental damage. A case study of Siwa oasis, Egypt Western Desert, is selected, seeking to build a tourism industry depending on its resources. This paper helps to evaluate the present state of tourism in Siwa oasis, to consider the prospects of tourism as a tool of development in the oasis and to establish guidelines for a sustainable development approach. A field survey was conducted based on qualitative approach, in order to investigate experts' opinions about the development of Siwa oasis as a tourist destination. Conclusions were focusing on the need to reassess tourism development process in the oasis, perceiving Siwa as a natural asset that needs to be preserved and confirming that as a result of overuse of resources it is important to discourage overdevelopment especially non ecological development projects, suggesting the application of strong sustainability criteria.
\end{abstract}

Keywords: fragile ecosystem, natural and cultural resources, tourism development, sustainability, natural reserves, visitor management, Siwa oasis.

\section{Introduction}

Egypt's Western Desert embraces an area of 681,000 square kilometers, about two-thirds of the whole area of Egypt. It is one of the most arid regions in the world. The best known amongst these oases are Siwa, Bahriyah, Farafra, Kharga 
and Dakhla. The region regained its importance through increasing governmental interest in redistributing the population by re-deploying the agricultural and industrial development further away the Nile Valley to what was called the new Valley (El Wadi El Gedied) in the Western Desert (Fakhry [1]). All Egypt's oases contain monuments which date from different periods of Egyptian history. Temples, painted tombs, the remains of towns, fortresses and Christian monuments exist in all the oases and point to a flourishing past at certain periods of their long history. Although the oases of the Western Desert have much in common, Siwa is still the most fascinating of all the oases, not only for its history, but because of its natural beauty and its people's culture and traditions. The area of Siwa is about 10,088 square kilometres. It lies about 18,00 meters below sea level . The population of Siwa Oasis reached about 25,000 inhabitants by 2008 . It has about 203 naturally flowing ancient springs which were constructed during the Roman times. Siwa's great present problem is not the scarcity of water; rather, it is one of too much water and not enough drainage. There are many flowing springs whose water goes unused; it drains into a salt lake, whose water level rises with much harm to the neighbouring cultivated land. Siwa has about 250,000 palm tree, which constitute the greatest source of income for the oasis NSA [2]. The Western desert and its five oases added new dimensions to the tourism map of Egypt. The area has become a leisure tourist destination for adventurers, sport lovers, scientists, geologists, and those who

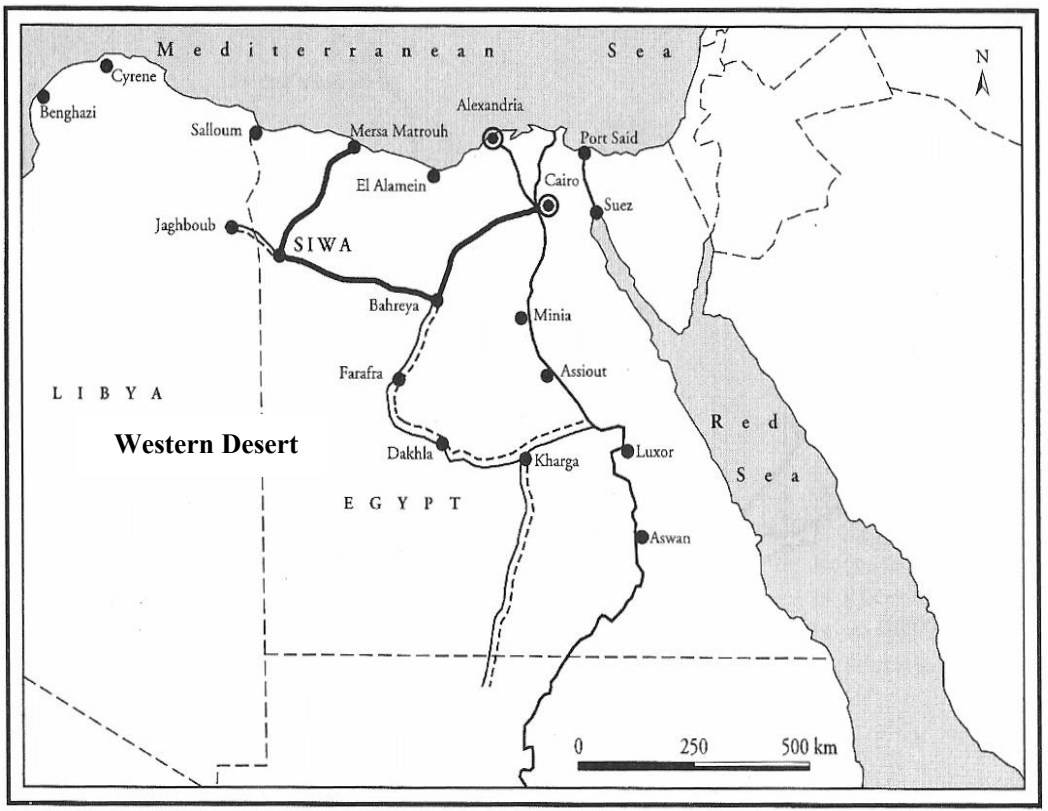

Figure 1: Map of Egypt demonstrating the Oases of the Western Desert. 
seek relaxation and natural therapy. The majority of Siwa's visitors are attracted by its entity as an oasis and its great reputation in ancient times. It is true that the severe hand of time, the ignorance of the inhabitants, and the disastrous effect of the salt in the soil are responsible for the ruinous condition and the destruction of many of these monuments; but no doubt what still remains repays the visit.

\section{Potentials of tourism development in Siwa}

Siwa oasis combines several potentials for tourism development which permit its conversion to a tourist destination offering a variety of the tourism product and encouraging tourism investments to the area, owing to its abundance of different tourism resources such as cultural/historic attractions, curative/therapeutic tourism and nature based tourism including, ecotourism and safari tourism. Siwa's historical sites include Shali Fortress, the temples of Amun, Cleopatra Spring, Fitnass Island, Al-Dakrur Mountain, and the Tombs of the Dead Mountain. Ecotourism indirectly can generate positive impacts by increasing political and economic support for natural area conservation, protection and management (Diamantis [3]). Local community in Siwa is involved in ecotourism operations in the provision of knowledge, services, facilities and locally produced products. Tourists visiting Siwa are considered "Special Interest Tourist". They are always seeking customized leisure and recreational experience driven by a specific expressed interest. The landscape of Siwa oasis is distinctive. Sandrifter is one small business committed to providing desert safari trips. The dynamic combination of climate, terrain, the scale of its iconic natural features and the history of human contact provides a variety of stimuli to engage domestic and international visitors. Siwa's natural reserve is characterized by its biological diversity presented in a variety of flora and fauna species in addition to its natural and cultural heritage importance which recommend it as one of the World Heritage Sites. The area is also characterized by its unique geological compositions consisting of humid land, sand dunes, hills and lakes. Concern has been given to this area applying ecotourism concept, protecting natural and historic fortunes within the area. The reserve consists of 3 sectors; the Eastern sector located in Quattara depression which combines areas such as Temira, Tabaghbagh, Al Arag, Al Bahrain, setra, and Nawamees. The middle sector which combine Beir wahed area and the Western sector located on the Libyan borders and combine Um Al Ghezlan and Shyata areas, Al Malfa and Gerba (Raafat [4]). The dilemma is that, the greater the exposure of these areas to visitors, the greater is the potential for negative visitor's impact to arise. The incidence of such impacts not only threatens the continued economic viability of the attraction sites as a commercial concern, but also raises serious questions about the sustainability of the attraction. Natural and cultural tourist attraction sites are under constant threat from the effects of overuse, pollution and the ravages of time. Environmental change is inevitable and is more obvious and pronounced in those areas that are sparsely populated and not subject to frequent high-volume tourist visits (Curtis [5]). 


\section{Siwa tourism development plan}

Within the framework of cooperation, applying the protocols signed with Matrouh governorate, the Egyptian Tourism Development Authority (TDA) started researches for the development of Siwa oasis, seeking the effective ways to promote the area as a tourist destination. The governorate of Matrouh put a comprehensive plan for Siwa development until 2020. The plan includes 17 development projects in different sectors; the most important projects include the establishment of (1) a factory for packing dates and olive for exporting, (2) a handicraft center to develop human resources, and (3) an industrial complex to produce salts both for local demand and exportation. Moreover, the plan includes (4) the establishment of tourist projects to promote curative / therapeutic tourism, safari, environmental and cultural tourism (TDA [6]). The first phase for proposed tourism development projects covers the following three sectors:

- Siwa City sector (El Dakrur Mountain center for curative tourism - area of 5 feddan* - 3 tourism projects registered - hotel capacity 393 bed).

- Al Zaitun Lake sector $35 \mathrm{~km}$ from siwa (Al Zaitun Lake center for resorts and safari tourism - area of 568 feddan* - 10 tourism projects registered - hotel capacity 3672 bed).

- Al Maraqi sector $20 \mathrm{~km}$ from siwa (Al Maraqi center for Heritage and ecotourism - area of 283 feddan* - 11 tourism projects registered - hotel capacity 1974 bed) TDA [7]

$* 1$ feddan $=1.04$ acres $=4200 \mathrm{~m}^{2}$

The aim from dividing Siwa oasis into sectors is to achieve a balance in the distribution of areas to avoid the concentration of development at specific locations. This may help in achieving integrated development, setting planning regulations and criteria, with regard to the fragile nature of the place.

\subsection{Egyptian - Italian environmental cooperation program}

With the funding of the Italian government and International Union for Conservation of Nature, and with the supervision of the Egyptian Environmental Affairs Agency (EEAA), under the Ministry of Environment, "Siwa Environmental Amelioration Project (SEAP)" implemented over two phases during the period May 1998-October 2003, was a project aiming to contribute to the conservation and sustainable use of natural and cultural resources of Siwa region. The working methodology has been based on participatory approach, seeking the full involvement of the local community, while respecting the Siwan traditions and culture. The foundation of the project was based on four components including: (1) development of Sustainable Agriculture; (2) strengthening the Siwan association; (3) strengthening Siwa protected area;

(4) solid waste management through developing and implementing a new SWM scheme in Siwa oasis and surrounding villages, based on the need of the Siwan community and in line with EEAA policies (Egyptian-Italian Environmental Cooperation Program [8]). 


\subsection{Role of private sector in Siwa local development}

Environmental Quality International (EQI), a consulting company providing services in environment and natural resources, has been privately investing in Siwa since 1997, engaging the Siwan community in every aspect and at every step of the process: project identification, implementation, and operation. EQI has implemented a series of community-based initiatives in Siwa that form a sustainable, private sector led development initiative, titled the "Siwa Sustainable Development Initiative". This initiative worked towards improving solid waste management practices, restoring traditional building techniques; revitalizing indigenous handicraft; and promoting small enterprises as well as participating in the rehabilitation of Siwa's marketplace and selected historic sites. EQI has also maintained an open dialogue with the Egyptian authorities, which proved to be extremely useful in reaching needed policy changes. This Initiative included: (1) The development of Adrere Amellal ecolodge in 1997; (2) the development of Shali Lodge located where lies the village of Siwa with its $13^{\text {th }}$-century-old enclave of Shali; (3) Siwan Women's Artisanship Development Initiative, launched in August 2001 as a community development intervention designed to increase the empowerment and economic selfsufficiency of Siwan woman through the revitalization of traditional handicraft production and the promotion of a culture of artisanship; in addition to (4) Participatory Art Events such as a land art event was organized in November 2003 by EQI and a British art dealer, in collaboration with members of the local community. The second Siwa Art project took place October 23-29, 2005. The famous Russian artists, Ilya and Emilia Kabakov displayed a work of "installation art" in participation with the Siwan community http://www.eqi.com.eg [9].

\section{Purpose of the study}

The objective of this research was to assess the current state of tourism in Siwa oasis, to consider the prospects of tourism as a tool of development in the oasis, to establish guidelines for a sustainable development and management approach applicable on cultural and natural fragile tourist destinations.

\section{Methodology}

\subsection{Qualitative research method}

Berg [10] differentiated between qualitative and quantitative research by identifying qualitative research as referring to meanings, concepts, definitions, characteristics, metaphors, symbols, description of things, whereas quantitative research as referring to counts and measures of things. Qualitative researchers are more interested in understanding individual and group perceptions of their environment (Bell [11]). Qualitative data sources include observation, field study, interviews, documents and texts, and researcher's impressions and reactions (Myers [12]). 


\subsection{Unstructured interviews}

A field survey was conducted based on qualitative approach using the unstructured interview technique, in order to investigate experts' opinions about the development of Siwa oasis as a tourist destination. A number of key points were prepared in advance to convey the focus of the interviews, allowing conversational flexibility, and enables experts to become more familiar with the research problem. The key points prepared were covering several areas such as; natural and cultural environments in Siwa, governmental efforts, private sector role, community involvement, tourism trends in Siwa etc. The questions asked were more likely to be open-ended, and data collected from different respondents were obviously different, and therefore not always comparable; this raised issues of reliability and validity for data collected.

\subsubsection{Data analysis method}

Qualitative Content Analysis goes beyond merely counting words to examining language intensely for the purpose of classifying large amounts of text into an efficient number of categories that represent similar meanings (Weber [13]). The goal of content analysis is "to provide knowledge and understanding of the phenomenon under study" and is congruent with the goal of the current study; as to provide knowledge and understanding about how far Siwa needs tourism development? Data analysis started with reading all data repeatedly to achieve immersion and obtain a sense of the whole (Tesch [14]) as one would read a novel. Then, data are read word by word to derive codes by first highlighting the exact words from the text that appear to capture key thoughts or concepts. Next, the researcher approached the text by making notes of her first impressions, thoughts, and initial analysis. As this process continues, labels for codes emerge that are reflective of more than one key thought. These often come directly from the text and are then become the initial coding scheme. Codes then are sorted into categories based on how different codes are related and linked. These emergent categories are to organize and group codes into meaningful clusters (Patton [15]). The verbatim quotations were subsequently analyzed using conventional qualitative content analysis technique. The elicited constructs were content analyzed. The researcher worked on transcribing the answers and setting basic codes for them, and then a coding frame was set. Codes were attached to phrases, sentences or whole paragraphs connected to a specific setting. Coding resulted in the identification of large segments of text on broad topics; these segments formed the basis for an in-depth analysis within or across topics.

\subsubsection{Interviews results and discussion}

The interviews started with questions that aimed at evaluating Siwa's natural and cultural environment current status. Experts were asked to justify their opinions. There was an agreement from experts upon the purity of Siwa's natural environment and the need to protect this valuable asset. Their comments came as follows: "In my opinion Siwa's natural environment has always been ideal in its purity of air and water. Since, the present development process started 15 years ago and this development ascended in time whereby several hotels including 
those environmentally -friendly hotels have been built and more tourists groups invaded this ideal oasis, I am afraid that the previous purity of air and water in that oasis is already affected to varying degrees. Therefore I hope that the Natural Environment in Siwa is not yet degraded and Siwa's unpolluted Natural Environment still prevails".

"In my opinion, the solution to preserve this natural asset is to announce Siwa as a protected area and therefore number of visitors and visitors' length of stay should be controlled and managed".

"I think Siwa has a pristine natural environment compared to other areas in Egypt. It is still unpolluted as it is not exposed to what most of the locations are exposed to due to its remoteness and isolation. And in my opinion, conservation of its high scenic and ecological qualities is desired".

Answers of public sector which support same opinions came as follows: "There is a fear from the alteration of the primitive fabric, the architectural character and the ecological values of the area, damaging in this way the identity of the locale or the sense of place. Tourism development may lead to improvements in local infrastructure and services to deal with attracted numbers of visitors but this should be achieved within a controllable framework".

"Pressure arising from Siwa's visitors may affect the quality of life of residents either positively or negatively. Positively, adding an economic value in other words economic benefit (i.e. job opportunities, keeping small local businesses viable, etc) making a contribution to revitalizing small, isolated communities such as Siwa oasis. At the same time, negative effects owing to pollution, noise and litter, and/or increased costs of living and land prices. Social conflicts may not appear in present time or during the current development stage but they may arise in the future as a result of pollution and crowding phenomenon leading to a tourism monoculture like what happened in places like Venice or Bruges".

Concerning the cultural environment, discussions covered Siwa's local heritage/historic sites and local traditions and norms. The answers of experts came to emphasize the idea that Siwa is attractive to visitors interested in culture and history not only its natural environment. A sample of comments was as follows: "The cultural environment in Siwa has been exemplary when Siwa was semi isolated in the desert and the road from Matrouh (North West coast) to Siwa was not yet developed at the time 30-40 years ago. As usual when such oasis as Siwa becomes a regular tourist destination for foreign tourists mainly and local tourists generally, certainly its cultural environment would be invadable and subject to change. That change while being modernized, it might still be culturally undesirable, and hopefully it will not deteriorate as time passes by".

Experts' answers reflected a high agreement on the importance of governmental efforts in improving Siwa and in particular in developing tourism. The following are examples of quotations that hold such meaning:

"Government role is really important but not yet as effective as it should be. Attention to Siwa from the government was only in the past ten years focusing on 
preserving the area's natural resources. Therefore there is always room for improvement particularly in hygiene and sanitation and in infrastructure and superstructure that would not negatively interfere with the distinction of general and tourism advantages that Siwa used to enjoy".

"Attention must be paid to public amenities such as toilets, drinking water, environmental health and safety, and emergency medical services provided for both local community as well as Siwa's visitors. Consideration should be given to availability and capacity levels in the context of visitor numbers and duration of stay and in the case of litter disposal, for example, strategically positioned collection points are really of great importance".

In the same sense, it is obvious from the following quotations that the experts' answers came to confirm that the role of the Private sector is also certainly important to develop tourism in Siwa but taking into consideration the fear from inwards investment that may alter the theme and authenticity of the oasis.

"However the lucrative outlook of private sector should not run primordially over the real and earnest efforts to develop that oasis touristically within the confine of its natural and cultural destiny. Therefore I am utterly against building grand hotels and monster establishments in an oasis such as Siwa in the name of developing tourism, as development should remain a keyword relative in its barring upon the natural ecosystem".

The following quotation exemplifies the opinion of private sector: "Vision for Siwa is to continue to work at developing it into a hub for sustainable development upon which it can become a model and an inspiration for destinations all over the world. I believe that the spirit of entrepreneurship at the smallest scale is what has preserved Siwa as thriving center for culture, tourism and trade; and that this spirit is the region's best hope for prosperity in today's economy. Investing in innovative ventures that channel the spirit toward sustainable development is what is really needed, seeking additional investment partners with the same guiding principles, to invest in the sustainable development of the oasis as well as other areas in the region".

Experts' answers concerning Community acceptance to tourism development in Siwa were as follows: "At the beginning Siwa population in general was quite conscious and proud of Siwa's unique endowment both natural and cultural and did not want any drastic change in that realm. Since tourism development started in Siwa some 15 years ago, community involvement began to move foreword hesitantly in order to safeguard Siwa's unique resources and at the same time benefit from the positive economic outcome of developing Siwa's attractions. At first local community was defending their oasis from any change, then they felt revenue i.e. economic benefits, so they started to sell their destination".

Experts were asked to give their opinion about Siwa as an Ecotourism and Curative destination. Their perception of Siwa as an Ecotourism destination came as follows:

"Ecotourism is presently considered on a world scale one of the most important tourism typologies that should be developed in a sustainable manner. Respecting and safeguarding the natural and cultural resources existing in the destination. Siwa being still a rich destination in its ecotourism attractions 
should be developed in a way that safeguard and protect its natural and cultural environments, in order to favorably compete with the major ecotourism destinations in the world such as Bali in Indonesia, Seychelles and Mauritiaus".

"There is no doubt that Siwa sells a unique product which is nature, as any destination can never compete with Luxor in Upper Egypt for its monuments and historical value, the same goes for Siwa as an ecotourism destination".

"One main argument concerning ecotourism is the two opposite poles of sustainability and profitability. All venues, in whatever industry, need a profit in order to continue operations. There is a fine line between the two functions, which needs to be maintained. As Siwa greatly depends on its natural environment, promoting and investing in ecotourism activities. It becomes increasingly important to develop a more long-term approach and to offer products and services that work with the environment in order to maintain sustainability".

As for Curative tourism in Siwa: "Curative tourism was always a target for the limited number of visitors who used to visit Siwa before the present tourism development process started. Still Siwa can be a Mecca for curative tourism if its tourism development process follows the sustainable path. In order for curative tourism in Siwa to continue the development process in Siwa should not invade the red contours of protecting and safeguarding its natural resources. This is not an easy task as it should always stand on the way of private investors who want always to reap the fruits of their development efforts in the shortest possible time. Even though such efforts would scarifies, even on the long run, the richness of curative tourism in Siwa".

"The problem with curative/therapeutic tourism is not related to Siwa in particular, but to Egypt in general although the availability of natural resources that proved efficient curative results, the reputation concerning public health and hygiene including air and water pollution still an obstacle facing Siwa as a curative tourism destination as well as other destinations such as Safaga in Red Sea, Ein el Sera in Al Fayoum, and Aswan in Upper Egypt".

Another important finding is that most of the experts were highly against traditional promotional channels, they stressed the cautious when promoting Siwa as a tourist destination. "I am against promoting areas with fragile ecosystem. The best channel will be publications specialized on environment locally and internationally, targeting responsible travellers following codes of conducts that help in diminishing negative impacts".

"The marketing of Ecolodges may play a vital role in promoting Siwa and its unique environment as the case of Adrere Amellal Ecolodge. The image being promoted may influence the type of visitor attracted and establish a contact with interested clients. In addition, it is important that marketing Siwa oasis takes a supply-led approach rather than a demand-led approach as to control number of tourists attracted to the oasis". 


\section{Limitations for the study}

The literature review found involving documented materials and statistical data related to Egypt's Western Desert and its oases especially Siwa and the surrounding area are limited, therefore primary data was essential.

The validity of the experts' interviews may be lowered due to the fact that the interviews were translated from Arabic to English. In the translation process words can unintentionally acquire wrong meaning. Revising interviews transcription more than once has hopefully helped to overcome this problem.

\section{Summary and findings}

The future of tourism development in Siwa is a sensitive issue. The findings of the study provide important insights into the value of careful development and planning of Siwa oasis as a tourist destination. Given the specific character of desert ecosystems, marked by great fragility as well as great poverty, tourism in Siwa oasis must be based on principles of precaution and effectiveness at two levels; with respect to the tourism activity itself, in order to minimize its negative impacts; and with respect to its role as a vehicle for developing desert destinations. This means that tourism in such remote and fragile areas must be economically viable, socially equitable, environmentally sustainable, and culturally diversified. Local population must be able to control conditions and guides choices within their own territories. The current study has drawn out some major findings. First, the majority of Siwa's visitors in addition to the participating experts perceived Siwa as a natural asset that need to be preserved. Second, both parties agreed that priority goes to infrastructure including solving drainage problem as to improve Siwa's local community way of life as well as its visitors' stay. Third, findings confirmed that as a result of overuse of resources it is important to discourage overdevelopment especially non ecological development projects. Fourth, the research illustrated that there are notable differences in tourists' behaviour towards destination environment protection either natural or cultural environment, which clarifies the importance of promoting visitors' codes of conduct in such areas. Fifth, the absence of site planning and management techniques is considered an obstacle to develop tourism in areas with fragile ecosystem such as the case of Siwa. Sixth, the study also stressed the need of the private sector role in initiating ecological development, and opening up viable business opportunities for Siwan local community, and therefore enhancing their skills and knowledge. Seventh, the study revealed the importance of the local community efforts in contributing to the preservation of Siwa's natural and cultural resources and in upgrading themselves coping with their lives' dependency on tourism. Eighth, ecotourism and curative tourism are new patterns of tourism that still need careful development to be offered by Siwa to the international market. Finally, the results of the study have revealed the importance of a delicate balance to be achieved among the objectives of ecotourism development, the conservation of natural and cultural heritage, and direct benefits to local communities. 


\section{Implications and recommendations}

All actors including local governmental bodies have an important role to play in promoting policies and adopting measures based on principles of sustainability, as adapted to the specific conditions of areas with fragile ecosystem such as oases located in deserts (WTO [16]). National and local governments have central responsibility for the success of sustainable strategies and for the implementation of action programs in support of responsible and ethical tourism. They should ensure that tourism remains a complementary activity, forming part of a comprehensive enhancement program for the oasis development. This means ensuring that tourism does not become a mono-activity or sole resource for Siwa and/or other areas with similar conditions.

In this respect, the key recommendations drawn from the results and analyses presented in the current study involve the following:

- Concerning the Natural/physical Environment:

- Ensuring the protection of biological diversity within protected areas and other fragile areas contributing towards conservation and tourism through the application of proposed management impacts techniques.

- Monitoring the evolving patterns of natural geographic suitability, that is, beyond the status of physical capability for development as measured through impact assessments and carrying capacity of various kinds-within such concepts and strategies as balance, diversity and complementarily.

- The protection of Siwa's cultural heritage:

- Enhancing the cultural wealth of Siwa's local community and their tangible and intangible heritage, but without converting traditions into commercialized "folklore" or looting archaeological sites, as its preservation is fundamental.

- Encouraging good practice and eliminating bad practice, in relation to the built environment as to ensure that all new development are adequate in terms of existing on-site services and infrastructure and are developed in a way that minimizes the use of natural resources.

- The Economic viability:

- Ensuring the economic viability of Siwa that requires all activities to be conducted with a view to sustainability objectives, particularly since the high levels of poverty tend to discourage long-term strategies in favour of short-term survival.

- Assisting the integration of tourism development in Siwa with other forms of economic and regional restructuring; so as to avoid inharmonious relationships.

- Various tourism trends in Siwa:

- Setting a marketing plan promoting Siwa as a fragile ecotourism destination focusing on marketing campaigns based on environmental themes and events.

- Improving medical hospitality through the provision of a specialized centre for natural therapy in addition to trained staff to promote Siwa as a Curative destination. 
- Private sector investing in tourism in Siwa:

- Giving concern to the accommodation sector in the regional development plan of Siwa oasis including existed, under construction and proposed hotel establishments taking into consideration construction restrictions, involving ecological criteria, physical carrying capacity in addition to the management and operation of these establishments.

- Better knowledge on the part of the industry to Siwa's visitors through "codes of conducts" included as "Ecotips" in brochures distributed, to guide tourists towards more sustainable behaviour would help reducing some of the negative environmental aspects of tourism.

- Offering environmentally integrated itineraries, by organizing camps selfmanaged by locals. Promoting financial support and the transfer of good practices- hygiene, food preparation, and environmental conservation as the basis for such itineraries.

- Local participation and control:

- Stressing the rationale for Siwa's community involvement in tourism planning process, and acknowledging the value of individuals to integrate all related skills and vocations (guide service, safari drivers, cooks, porters, local handicrafts etc) into the tourism product making use of their know-how and local knowledge of their special environment and reducing potential conflicts.

- $\quad$ Ensuring local community welfare and visitor satisfaction, these encounters must be organized with respect and regard for authenticity, avoiding all forms of discrimination.

The issue of developing tourism in remote, fragile ecosystem such as the case of Siwa oasis is still wide open for exploration. It is a complex field, which demands specific comprehensive of multiple disciplines. Further research to be done may include sustainable development of tourism in deserts considered on its own terms, with due regard for its special character.

\section{References}

[1] Fakhry, A., Siwa Oasis, American University in Cairo, pp.70-179, 2005.

[2] NSA, Discovering Siwa,Native Siwan Association for Tourist Services and Environmental Protection, Siwa, Egypt, pp. 9-51, 2009.

[3] Diamantis, D., Ecotourism Management and Assessment, Thomson Learning, London. pp. 27-62, 2004.

[4] Raafat, A., North West Mediterranean and the Oases: Leisure Tourism in Egypt: West of the Nile, Inter-Consult Research Center Vol.1, pp. 64-96, 2001.

[5] Curtis, S., Visitor management in small historic cities, Travel and Tourism Analyst, Vol.3, pp. 75-89, 1998.

[6] TDA, Tourism Development Authority, Siwa oasis Tourism Development, Phase 2 Indicative Plans, 2000.

[7] TDA, Tourism Development Authority, Siwa Future and Integrated Development, 2001. 
[8] Egyptian-Italian Environmental Cooperation Program, Siwa Environmental Amelioration Project, Second Phase, Project Document, revised, p. 119, October 2002, http://www.eiecop.org.

[9] EQI, Environmental Quality International, http://www.eqi.com.eg, last access: November 2008.

[10] Berg, B., Qualitative Research Methods for the Social Sciences, $4^{\text {th }}$ edn., Allyn and Bacon, Boston, 2001.

[11] Bell, J., Doing Your Research Project, Open University Press, Milton Keynes, 1992.

[12] Myers, M., Qualitative Research in Information Systems, 2000. URL http://www.auckland.ac.nz/msis/isworld/index.htm

[13] Weber, Basic Content Analysis, $2^{\text {nd }}$ ed., Sage Publications, UK, 1990.

[14] Tesch, R., Qualitative research: Analysis types and software tools, Falmer Press, New York, 1990.

[15] Patton, M., Qualitative Research and Evaluation Methods, $3^{\text {rd }}$ edn., Sage, Thousand Oaks, CA, 2002.

[16] WTO, Sustainable Development of Tourism in Deserts: Guidelines for Decision Makers, World Tourism Organization, Madrid, Spain, 2007. 